Bangladesh J. PI. Breed. Genet, 24(1): 33-40

\title{
INHERITANCE OF FERTILITY RESTORATION INVOLVING WILD ABORTIVE CYTOPLASMIC MALE STERILITY SYSTEM IN RICE (Oryza sativa L.)
}

\author{
M. J. Hasan, M. U. Kulsum, A. Ansari, A. K. Paul and P. L. Biswas \\ Hybrid Rice Section \\ Bangladesh Rice Research Institute \\ Gazipur 1701, Bangladesh
}

\begin{abstract}
Inheritance of fertility restoration was studied in crosses involving ten elite restorer lines of rice viz. BR6839-41-5-1R, BR7013-62-1-1R, BR7011-37-1-2R, BR10R, BR11R, BR12R, BR13R, BR14R, BR15R and BR16R and one male sterile line Jin23A with WA sources of cytoplasmic male sterility. The segregation pattern for pollen fertility of $\mathrm{F}_{2}$ and $\mathrm{BC}_{1}$ populations of crosses involving Jin23A indicated the presence of two independent dominant fertility restoring genes. The mode of action of the two genes varied in different crosses revealing three types of interaction, i.e. epistasis with dominant gene action, epistasis with recessive gene action, and epistasis with incomplete dominance.
\end{abstract}

Key words: Rice (Oryza sativa), CMS, fertility restoration, inheritance

\section{INTRODUCTION}

Precise understanding of genetics of fertility restoration is useful in planning a sound breeding strategy for development of superior restorers in a hybrid breeding program. It may also help in the efficient transfer of restorer genes into other agronomical desirable genotypes. In rice, several sources of cytoplasmic genetic male sterility (CMS) have been reported (Virmani and Edwards, 1983). However, extensive research work on identification of restorers and maintainers and on inheritance of fertility restoration has been done on the WA (Wild Abortive) type cytoplasmic source only. Cytoplasmic male sterility (CMS), which causes the production of non-functional pollen and inherited maternally, is important in commercial hybrid seed production (Kaul, 1988) and breeding programmes. A number of studies on the relationship between CMS and fertility-restorer genes $(R f)$ have been conducted in various plants and may enable a better understanding of genetic differentiation and the interaction between cytoplasmic and nuclear genomes in plants (Budar and Pelletier, 2001).

The wild-abortive (WA) type of CMS in rice has been used extensively in commercial production, and its fertility is sporophytically restored by the dominant restorer genes (Shen et al., 1998, Jing et al., 2001). Fertility-restorer genes are important in the production of hybrid rice. Although a variable number of restorer genes have been proposed in various restorer lines, one or two dominant restorer alleles ( $R f 3$ and $R f 4)$ are usually suggested to be responsible for the fertility (Yao et al., 1997, Tan et al., 1998). A major dominant gene with sporophytic action has been reported to be involved in fertility restoration of the WA source (Huang et al., 1986, Zhang and Shen, 1987). However, most studies involving restorers of WA cytoplasm suggest the presence of two pairs of independent, dominant fertility restorer genes with one gene pair being stronger in action than the other (Yang and Lu, 1984k, Li and Yuan, 1986, Zhang and Lu, 1987, Raj and 
Virmani, 1988, Muker 1990). The maintenance and transference of CMS within natural population of wild rice cannot be separated from $R f$ and it is easy to assume that the restorer genes exist in wild rice. However, the information about the origin, evolutionary relationships and distribution of the fertility-restorer genes for WA-CMS system is fragmentary. To be able to recognize the $R f$ in wild rice would facilitate not only the exploitation of new $R f$ alleles but also give a better understanding of the origin and evolution of the fertility-restorer genes. With this view, the present study was undertaken to determine the genetic control of fertility restoration of WA-CMS system.

\section{MATERIALS AND METHODS}

The experiment was conducted at the experimental field of Bangladesh Rice Research Institute (BRRI), Gazipur. Three consecutive seasons such as Boro 2008-09, T. Aman 2009 and Boro 2009-10 has been deployed for this experiment. The material consisted of one male sterile line Jin23A belonging to WA type source of cytoplasmic male sterility and ten prospective restorer lines. The restorer lines were BR6839-41-51R, BR7013-62-1-1R, BR7011-37-1-2R, BR10R, BR11R, BR12R, BR13R, BR14R, BR15R and BR16R. First season $F_{1}$ was raised. The resulting $F_{1}$ 's were selfed as well as backcrossed with their respective female parents to generate $\mathrm{F}_{2}$ and $\mathrm{BC}_{1}$ populations in the second season and final season evaluation was made with pollen and spikelet fertility of each plant in the $\mathrm{F}_{2}$ and $\mathrm{BC}_{1}$ populations. From each plant, five anthers from different spikelets were collected and their pollen grains were stained in $1 \%$ Iodine Potassium Iodide (IKI) solution. Plants were classified on the basis of pollen fertility analysis as fertile (61-100\% pollen stained), partially fertile (31-60\%), partially sterile (1-30\%) and sterile $(<1 \%)$ based on their shape and extend of staining under an optical microscope. One panicle from each plant was bagged before flowering for spikelet fertility analysis and spikelet fertility of bagged panicle was count at maturity stage. At maturity, the bagged panicle was examined for seed set and classified as fertile (81-100\% seed set), partially fertile $(31-80 \%)$, partially sterile $(1-30 \%)$ and sterile $(<1 \%)$. The parental lines, $\mathrm{F}_{1}$ progenies, $250 \mathrm{~F}_{2}$ plants for each segregating population were grown and evaluated in the same conditions for phenotypic and pollen fertility rate was used as the main criteria for the evaluation of fertile and sterile plants. $F_{1}$ 's contained two rows, $F_{2}$ seven rows, $\mathrm{BC}_{1}$ five rows with 37 plants/row and non replicated. For inheritance analysis plants with less than $1 \%$ stained pollen were categorized into the sterile class, and all others were regarded as fertile. Chi-square analysis was used to estimate the distribution pattern of $R f$ alleles with WA type source of CMS lines. Measurement of pollen fertility was made on all plants in each of the entries. Twenty to thirty spikelets were collected from each primary panicle and fixed in $70 \%$ alcohol. From these spikelets 10-12 anthers were collected at random and smear in IKI $(1 \%)$ and examined under optical microscope. Plants were classified on the basis of pollen fertility analysis as fertile $(61-100 \%$ pollen stained), partially fertile (31-60\%), partially sterile $(1-30 \%)$ and sterile $(<1 \%)$ based on their shape and extend of staining under an optical microscope. The pollen fertility were computed and expressed in percentage for each $\mathrm{F}_{1}, \mathrm{~F}_{2}$ and $\mathrm{BC}_{1}$ population as follows:-

$$
\begin{aligned}
& \text { Pollen fertility }(\%)=\frac{\text { Number of fertile pollen grains }}{\text { Number of sterile }+ \text { Number of fertile }} \times 100 \\
& \text { pollen grains pollen grains }
\end{aligned}
$$


At maturity, the bagged panicle was examined for seed set and classified as fertile (71$100 \%$ seed set), partially fertile $(31-70 \%)$, partially sterile $(1-30 \%)$ and sterile $(<1 \%)$.

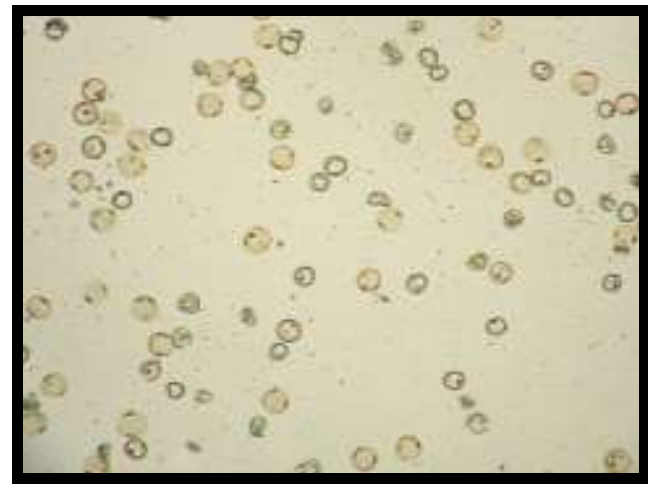

Completely sterile pollen

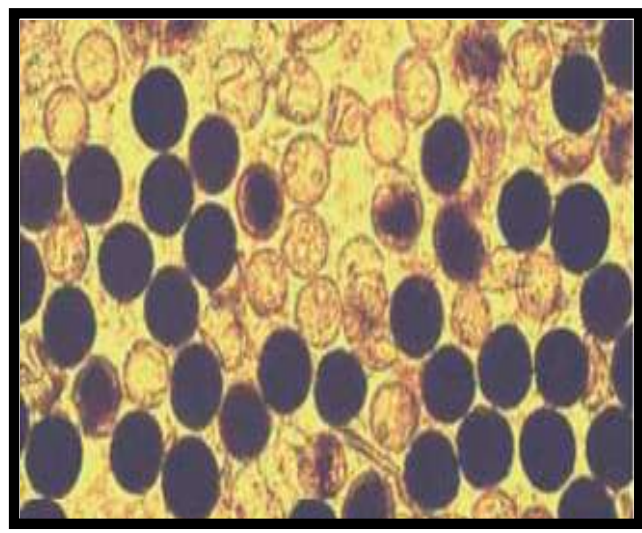

Partially fertile pollen

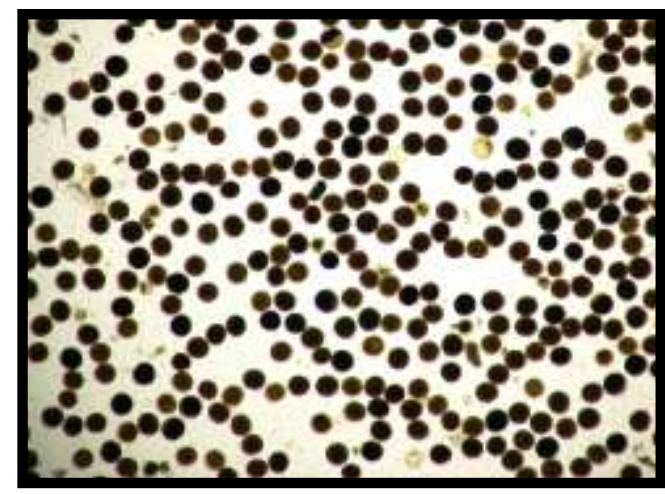

Full fertile pollen

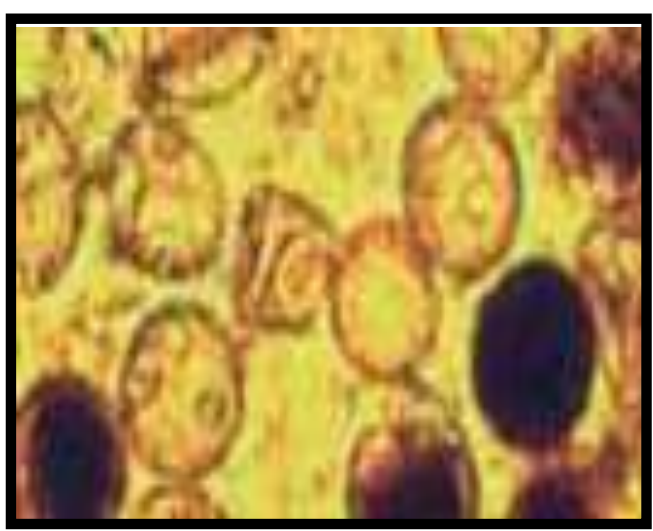

Partially sterile pollen

Plate1. Pollen image categorized as completely sterile, full fertile, partially fertile and partially sterile

\section{RESULTS AND DISCUSSION}

Pollen fertility, spikelet fertility and standard error of mean of $\mathrm{F}_{1}$ 's along with their parents were shown in Table 1. Pollen fertility of $F_{1}$ ranged from $71-85 \%$ and the highest was obtained from Jin23A/BR15R while the lowest from Jin23A/BR14R. On the other hand, spikelet fertility of the same cross combinations ranged from $71-82 \%$ and suggested that pollen fertility little bit differ with spikelet fertility at the time of maturity. It might be due to pollen abortion at different cell division stage. Pollen fertility and spikelet fertility of the parents ranged from $72-88 \%$ and $71-82 \%$ respectively. According to pollen and spikelet fertility classification category all entries fallen into fertile class.

Segregation patterns for pollen fertility in $\mathrm{F}_{2}$ population of Jin23A with ten restorer lines are stated in Table 2 . The pollen fertility results indicated that relatively few genes were involved in fertility restoration in the crosses studied. $\mathrm{Li}$ and $\mathrm{Zhu}$ (1988) have reported that the $R f$ exist mainly in the varieties from Southern Asia and South-eastern Asia and the varieties from North America, Latin America and Africa have no restoring ability. 
Table1. Pollen fertility (\%) and spikelet fertility (\%) of $\mathrm{F}_{1}$ plants of an $\mathrm{A} / \mathrm{R}$ crosscombination for WA CMS system using ten different restorer lines

\begin{tabular}{l|c|c|c}
\hline \multicolumn{1}{c}{ Cross combination } & Pollen fertility $(\%)$ & Spikelet fertility $(\%)$ & Fertility status \\
\hline Jin23A/BR6839-41-5-1R & $81 \pm 1.15$ & $82 \pm 0.58$ & Fertile \\
Jin23A/BR7013-62-1-1R & $77 \pm 0.58$ & $80 \pm 2.08$ & Fertile \\
Jin23A/BR7011-37-1-2R & $77 \pm 1.73$ & $77 \pm 1.53$ & Fertile \\
Jin23A/BR10R & $81 \pm 0.58$ & $77 \pm 2.52$ & Fertile \\
Jin23A/BR11R & $73 \pm 1.15$ & $74 \pm 2.31$ & Fertile \\
Jin23A/BR12R & $74 \pm 1.53$ & $73 \pm 1.00$ & Fertile \\
Jin23A/BR13R & $77 \pm 0.58$ & $75 \pm 1.15$ & Fertile \\
Jin23A/BR14R & $71 \pm 0.58$ & $72 \pm 2.52$ & Fertile \\
Jin23A/BR15R & $85 \pm 1.15$ & $81 \pm 2.08$ & Fertile \\
Jin23A/BR16R & $74 \pm 1.15$ & $71 \pm 1.15$ & Fertile \\
\hline Restorer line & & & \\
\hline BR6839-41-5-1R & $82 \pm 1.53$ & $80 \pm 1.00$ & Fertile \\
BR7013-62-1-1R & $79 \pm 0.58$ & $75 \pm 1.53$ & Fertile \\
BR7011-37-1-2R & $76 \pm 1.53$ & $74 \pm 3.21$ & Fertile \\
BR10R & $88 \pm 1.15$ & $80 \pm 2.08$ & Fertile \\
BR11R & $76 \pm 2.08$ & $71 \pm 2.31$ & Fertile \\
BR12R & $76 \pm 0.58$ & $72 \pm 1.53$ & Fertile \\
BR13R & $79 \pm 1.53$ & $71 \pm 3.21$ & Fertile \\
BR14R & $74 \pm 2.52$ & $72 \pm 1.15$ & Fertile \\
BR15R & $87 \pm 3.06$ & $80 \pm 0.58$ & Fertile \\
BR16R & $72 \pm 2.65$ & $72 \pm 3.06$ & Fertile \\
\hline
\end{tabular}

In the present study, the cross combination Jin23A/BR6839-41-5-1R expressed fertility restoration in $\mathrm{F}_{2}$ as segregating ratio of 12:3:1 (FF: SF: CS), indicating the involvement of two dominant genes which exhibit dominant epistasis. This suggested that two independently segregating dominant genes seem to control the fertility restoration. The effect of one of the two genes in restoring fertility appeared to be stronger than the other. This indicated that the dominant gene alone could control the fertility restoration. The $\mathrm{F}_{2}$ population of the cross Jin23A/ BR7011-37-1-2R, Jin23A/BR10R, Jin23A/BR11R, Jin23A/BR13R and Jin23A/BR14R exhibited a similar trend of segregation ratio of 12:3:1 of FF: SF: CS type of plants, indicating the epistasis with dominant type gene action controlled by two independently segregating dominant genes.

Again, While the CMS line Jin23A was crossed with the restorer line BR12R, the $F_{2}$ segregation pattern for pollen fertility fell into the digenic ratio 9:3:4 (FF:SF:CS). The results indicated the involvement of two independently segregating dominant genes with recessive epistatic interaction control the fertility restoration of BR12R. Assuming that two dominant fertility restoring genes involved in this action but one of the two genes appeared more effective than the other. The $F_{2}$ ratio of 9:3:4 involving supplementary or epistasis with recessive gene action has been reported earlier by Bharaj et al., (1991) and Hossain et al., (2010) in WA type sources of CMS lines. Again when the CMS lines crossed with the restorer line BR7013-62-1-1R, the $F_{2}$ segregation for pollen fertility showed semi-epistasis ratio 9:6:1 (FF: SF: CS). This variation in the behavior of fertility restoring genes could be due to either the presence of different restoring genes in the ten restorers studied or differential penetrance and expressivity of these restorer genes depending on the nuclear genotype of the female parent. Continuous variation with regard to pollen fertility is generally attributed to modifier genes and environmental influences. 
Table 2. Segregation for pollen fertility restoration in $\mathrm{F}_{2}$ populations involving WA type source of CMS line Jin23A

\begin{tabular}{|c|c|c|c|c|c|c|c|c|c|c|}
\hline \multirow[t]{2}{*}{ Cross combination } & \multirow[t]{2}{*}{ Generation } & \multirow{2}{*}{$\begin{array}{l}\text { Total no. of plants } \\
\text { scored }\end{array}$} & \multicolumn{5}{|c|}{$\begin{array}{l}\text { Segregation pattern: No. of plants } \\
\text { with pollen fertility reaction }\end{array}$} & \multirow{2}{*}{$\begin{array}{l}\text { Genetic ratio } \\
(\mathrm{FF}: \mathrm{SF}: \mathrm{CS})\end{array}$} & \multirow[t]{2}{*}{$\chi^{2}$ value } & \multirow[t]{2}{*}{ p-value } \\
\hline & & & FF & PF & PS & SF & $\mathrm{CS}$ & & & \\
\hline Jin23A/BR6839-41-5-1R & $\mathrm{F}_{2}$ & 175 & 123 & 22 & 18 & 40 & 12 & 12:03:01 & 2.206 & $0.50-0.25$ \\
\hline Jin23A /BR7013-62-1-1R & $\mathrm{F}_{2}$ & 175 & 107 & 40 & 18 & 58 & 10 & 9:06:01 & 1.711 & $0.50-0.25$ \\
\hline Jin23A/BR7011-37-1-2R & $\mathrm{F}_{2}$ & 175 & 135 & 16 & 14 & 30 & 10 & 12:03:01 & 0.429 & $0.90-0.75$ \\
\hline Jin23A/BR10R & $\mathrm{F}_{2}$ & 175 & 140 & 14 & 13 & 27 & 8 & 12:03:01 & 2.402 & $0.50-0.25$ \\
\hline Jin23A/BR11R & $\mathrm{F}_{2}$ & 175 & 125 & 21 & 20 & 41 & 9 & 12:03:01 & 2.684 & $0.50-0.25$ \\
\hline Jin23A/BR12R & $\mathrm{F}_{2}$ & 175 & 105 & 16 & 17 & 33 & 37 & 9:03:04 & 1.480 & $0.50-0.25$ \\
\hline Jin23A/BR13R & $\mathrm{F}_{2}$ & 175 & 131 & 16 & 14 & 30 & 14 & 12:03:01 & 1.100 & $0.75-0.50$ \\
\hline Jin23A/BR14R & $\mathrm{F}_{2}$ & 175 & 128 & 18 & 16 & 34 & 13 & 12:03:01 & 0.512 & $0.90-0.75$ \\
\hline Jin23A/BR15R & $\mathrm{F}_{2}$ & 175 & 99 & 42 & 21 & 63 & 13 & 9:06:01 & 0.497 & $0.90-0.75$ \\
\hline Jin23A/BR16R & $\mathrm{F}_{2}$ & 175 & 101 & 45 & 20 & 65 & 9 & 9:06:01 & 0.416 & $0.90-0.75$ \\
\hline
\end{tabular}

$\mathrm{FF}=$ Full fertile, $\mathrm{PF}=$ Partial fertile, $\mathrm{PS}=$ Partial sterile $, \mathrm{PF}+\mathrm{PS}=\mathrm{SF}($ Semi fertile $), \mathrm{CS}=$ Complete sterile 
Table 3. Segregation for pollen fertility restoration in $\mathrm{BC}_{1}$ populations involving WA sources of CMS line Jin23A

\begin{tabular}{|c|c|c|c|c|c|c|c|c|c|c|}
\hline \multirow[t]{2}{*}{ Cross combination } & \multirow[t]{2}{*}{ Generation } & \multirow{2}{*}{$\begin{array}{c}\text { Total no. of } \\
\text { plants scored }\end{array}$} & \multicolumn{5}{|c|}{$\begin{array}{l}\text { Segregation pattern: No. of plants } \\
\text { with pollen fertility reaction }\end{array}$} & \multirow{2}{*}{$\begin{array}{l}\text { Genetic ratio } \\
\text { (FF:SF:CS) }\end{array}$} & \multirow[t]{2}{*}{$\chi^{2}$ value } & \multirow[t]{2}{*}{ P-value } \\
\hline & & & FF & PF & $\mathrm{PS}$ & SF & $\mathrm{CS}$ & & & \\
\hline Jin23A//Jin23A/BR6839-41-5-1R & $\mathrm{BC}_{1}$ & 120 & 65 & 10 & 20 & 30 & 25 & $2: 01: 01$ & 1.25 & $0.75-0.50$ \\
\hline $\mathrm{Jin} 23 \mathrm{~A} / / \mathrm{Jin} 23 \mathrm{~A} / \mathrm{BR} 7013-62-1-1 \mathrm{R}$ & $\mathrm{BC}_{1}$ & 110 & 33 & 9 & 42 & 51 & 26 & $1: 02: 01$ & 1.47 & $0.50-0.25$ \\
\hline Jin23A//Jin23A/BR7011-37-1-2R & $\mathrm{BC}_{1}$ & 80 & 35 & 8 & 12 & 20 & 25 & 2:01:01 & 1.88 & $0.50-0.25$ \\
\hline Jin23A//Jin23A/BR10R & $\mathrm{BC}_{1}$ & 100 & 49 & 12 & 18 & 30 & 21 & $2: 01: 01$ & 1.66 & $0.50-0.25$ \\
\hline $\operatorname{Jin} 23 \mathrm{~A} / / \mathrm{Jin} 23 \mathrm{~A} / \mathrm{BR} 11 \mathrm{R}$ & $\mathrm{BC}_{1}$ & 85 & 40 & 7 & 15 & 22 & 23 & $2: 01: 01$ & 0.32 & $0.90-0.75$ \\
\hline Jin23A//Jin23A/BR12R & $\mathrm{BC}_{1}$ & 107 & 31 & 11 & 16 & 27 & 49 & 1:01:02 & 1.06 & $0.75-0.50$ \\
\hline Jin23A//Jin23A/BR13R & $\mathrm{BC}_{1}$ & 105 & 50 & 13 & 19 & 32 & 23 & $2: 01: 01$ & 1.78 & $0.50-0.25$ \\
\hline Jin23A//Jin23A/BR14R & $\mathrm{BC}_{1}$ & 95 & 47 & 12 & 15 & 27 & 21 & 2:01:01 & 0.77 & $0.75-0.50$ \\
\hline $\operatorname{Jin} 23 \mathrm{~A} / / \operatorname{Jin} 23 \mathrm{~A} / \mathrm{BR} 15 \mathrm{R}$ & $\mathrm{BC}_{1}$ & 75 & 22 & 10 & 25 & 35 & 18 & 1:02:01 & 0.76 & $0.75-0.50$ \\
\hline Jin23A//Jin23A/BR16R & $\mathrm{BC}_{1}$ & 115 & 33 & 15 & 40 & 55 & 27 & 1:02:01 & 0.84 & $0.75-0.50$ \\
\hline
\end{tabular}

$\mathrm{FF}=$ Full fertile, $\mathrm{PF}=$ Partial fertile, $\mathrm{PS}=$ Partial sterile $, \mathrm{PF}+\mathrm{PS}=\mathrm{SF}($ Semi fertile $), \mathrm{CS}=$ Complete sterile 
Similar trend were observed in $\mathrm{F}_{2}$ population with restorer line BR15R and BR16R. For further confirmation of the segregation patterns, pollen fertility of $\mathrm{BC}_{1}$ generations were also studied and presented in Table 3.

The pollen fertility analysis in crosses involving Jin23A with BR6839-41-5-1R, BR7011-37-1-2R, BR10R, BR11R, BR13R and BR14R indicated segregation ratios of 12:3:1 and 2:1:1 of full fertile, semi fertile and complete sterile plants in $F_{2}$ and $\mathrm{BC}_{1}$ generation, respectively. This suggested that the restorer lines BR6839-41-5-1R, BR7011-37-1-2R, BR10R, BR11R, BR13R and BR14R carried two independent dominant fertility restoring genes and one of the two genes had a duplicate effect that expose higher expression than the other gene and it alone could restorer fertility (dominant epistasis). Similar findings have been reported by Yang and $\mathrm{Lu}$ (1984). On the other hand, the crosses of Jin23A with BR7013-62-1-1R, BR15R and BR16R displayed epistasis with incomplete dominance as their $\mathrm{F}_{2}$ and $\mathrm{BC}_{1}$ populations segregated in 9:6:1 and 1:2:1 ratios, respectively, for full fertile, semi fertile and complete sterile plants. The cross Jin23A with BR12R showed segregation ratio in $\mathrm{F}_{2}$ and $\mathrm{BC}_{1}$ populations as 9:3:4 and 1:1:2 indicated the pattern of recessive epistasis. This finding is in line with the findings of Sohu and Phul (1995) but cyto sources of the CMS line was Gambiaca. From this, it is clearly evident that WA sources of CMS line Jin23A followed similar pattern of fertility restoration system like Gambiaca sources of CMS lines.

\section{CONCLUSION}

Based on the results obtained, it was concluded that the inheritance of male sterility and fertility restoration was conditioned by a pair of alleles, dominant and recessive, at a single locus interacting with the male sterile cytoplasm, and that the mode of action of the two genes varied in different crosses revealing three types of interaction, i.e. epistasis with dominant gene action, epistasis with recessive gene action, and epistasis with incomplete dominance.

\section{REFERENCES}

Bharaj, T. S., S. S. Bains, G. S. Sidhu and M. R. Gagneja. 1991. Genetics of fertility restoration of 'Wild Abortive' cytoplasmic male sterility in rice, Oryza sativa L. Euphytica 56: 199-203.

Budar, F and G. Pelletier 2001. Male sterility in plants: occurrence, determinism, significance and use. Life Science. 324: 543-550.

Hossain, M. S., A. K. Singh and F. Zaman. 2010. Genetics of fertility restoration of indica/japonica derivative restorers. Science Asia. 36: 94-99.

Huang, C. S., T. H. Tseng and C. Liu 1986. Inheritance of fertility restoration of cytoplasmic male sterility in indica rice. In: Rice Genetics. Proc. Int. Rice Genet. Symp. 27-31

Jing, R. C., X. M. Li, P. Yi and Y. G. Zhu. 2001. Mapping fertility-restoring genes of rice WA cytoplasmic male sterility using SSLP markers. Botanical Bulletin of Academia Sinica 42: 167-171.

Kaul, M. L. H. 1988. Male sterility in higher plants. In: Frankel R, Grossman M, Maliga P, Riley R, eds. Monographs of Theoretical Applied Genetics 10. Heidelberg: Springer-Verlag, 775-797.

Li, Y. C. and L. P. Yuan 1986. Genetic analysis of fertility restoration in male sterile lines of rice. In: Rice Genetics. Proc. Int. Rice Genet. Symp. 27-31 May, 1985. IRRI, Manila, Philippines, pp. 617-632. 
Li, Z. B and Y. G. Zhu. 1988. Rice male sterile cytoplasm and fertility restoration. In: Hybrid rice- Proceedings of the International Symposium on hybrid rice. Manila: International Rice Research Institute. Pp. 85-102

Muker, H. S. 1990. Studies of male sterility fertility restoration and seed set in hybrid rice. PhD. Diss., Punjab Agric. Univ., Ludhiana, India.

Raj, K. G. and S. S. Virmani 1988. Genetics of fertility restoration of "WA" type cytoplasmic male sterility in rice. Crop Sci. 28: 787-792.

Shen, Y. W.; Z. Q. Guan, J. Lu, J. Y. Zhuang, K. L. Zheng, M. W. Gao and X. M. Wang. 1998. Linkage analysis of a fertility restoring mutant generated from CMS rice. Theoretical and Applied Genetics 97: 261-266.

Sohu, V. S, and P. S. Phul. 1995. Inheritance of fertility restoration of three source of cytoplasmic male sterility in rice. J Genet Breed 49, 93-6.

Tan, X. L.; A. Vanavichit, S. Amornsilpa and S. Trangoonrung 1998. Genetic analysis of rice CMS-WA fertility restoration based on QTL mapping. Theoretical and Applied Genetics 96: 994-999.

Virmani,, S. S. and L. B. Edwards 1983. Current status and future prospects for breeding hybrid rice and wheat. Adv. Agron. 36: 145-214.

Yang, R. C. and H. R. Lu 1984. Preliminary analysis of restorer genes in the rice restorer line IR 24. Acta Agron. Sin. 10: 81-86.

Yao, F. Y.; C. G. Xu, S. B. Yu, J. X. Li, Y. J. Gao, X. H. Li and Q. F. Zhang 1997. Mapping and genetic analysis of two fertility restorer loci in the wild-abortive cytoplasmic male sterility system of rice (Oryza sativa L.). Euphytica 98: 183187.

Zhang, G. Q. and Y. G. Lu 1987. Genetic analysis for the cytoplasmic nuclear sporophytic male sterility in rice, Acta Agron. Sin. 13: 23-28.

Zhang, W. G. and Z. T. Shen 1987. Genetic analysis for fertility restoring genes in some varieties of rice (Oryza sativa L.). Acta Agron. Sin. 13: 97-101. 